\title{
Nutritional, physical and sensory properties of extruded products from high-amylose corn grits
}

\author{
Linsan Liu, Silu Li, Yuyue Zhong, Yibo Li, Jianzhou Qu, Jiaojiao Feng, Shutu Xu, Renhe Zhang, \\ Jiquan Xue, Dongwei Guo*
}

Key Laboratory of Biology and Genetic Improvement of Maize in Arid Area of Northwest Region, Ministry of Agriculture, College of Agronomy, Northwest A\&F University, Yangling Shaanxi, 712100, China

\section{A B S T R A C T}

To investigate the applicability of high-amylose corn grits (HACG) to the process for extruded products, a single screw extruder was used to produce extrudates under feed rate of $220 \mathrm{~g} / \mathrm{min}$, barrel temperature of $120^{\circ} \mathrm{C}$, and screw rotational speed of $150 \mathrm{rpm}$. The nutritional, physical and sensory properties were investigated in the HACG extrudate and normal corn grits (NCG) extrudate acting as control. The results indicated that the HACG extrudate had higher ( $\mathrm{P} \leq 0.05)$ protein $(7.07 \%)$, fiber $(5.41 \%)$, lipid $(1.48 \%)$, ash $(0.76 \%)$, resistant starch $(2.89 \%)$, zein $(4.65 \%)$, calcium $(22.34 \mathrm{mg} / \mathrm{kg})$, magnesium $(718.63 \mathrm{mg} / \mathrm{kg})$, iron $(19.47 \mathrm{mg} / \mathrm{kg})$, zinc $(22.73 \mathrm{mg} / \mathrm{kg}) \mathrm{contents}$ and 16 of 17 types of amino acids compared to the NCG extrudate. In regards to physical properties, the bulk density (BD), radial expansion index (REI) and water solubility index (WSI) values of the HACG extrudate, which were $57.94 \mathrm{mg} / \mathrm{ml}, 45.47$ and 43.25 , respectively, were significantly lower $(P \leq 0.05)$ than those of the NCG extrudate. However, the HACG extrudate had a higher special length (SL), indicating a higher axial expansion, water absorption index (WAl), frangibility and cohesiveness $(7.34 \mathrm{~cm} / \mathrm{g}, 3.69,68.79$ and 0.32 , respectively), and a more sponge-like structure. A sensory analysis indicated that the HACG extrudate had higher values for frangibility, cohesiveness, chewiness and overall taste with a lower coarseness and adhesiveness (to teeth).

Keywords: High-amylose corn; Extrudate; Physical; Nutritional; Sensory properties

\section{INTRODUCTION}

Extrusion has become a popular processing technology that is used to produce a wide variety of products, such as snack foods, breakfast cereals and pet foods, because of its higher productivity, richer functionality and lower operating costs compared to other cooking processes (Ficarella et al., 2006; Kasemsadeh, 2011). Extruded foods are composed mainly of starches, cereals, and/or vegetable proteins. Corn grains are a major ingredient in extruded foods, such as ready-to-eat breakfast cereals and snacks (Gujral et al., 2001). However, corn-based extruded products are energydense and nutrient-poor foods with a high glycemic index because they have a high starch content but lack nutritional value in terms of vitamins, minor minerals, proteins, amino acids and fiber (Brennan et al., 2013). Most studies have successfully improved the nutritional profile of extruded products by incorporating some nutrient-rich materials in the raw material (Liu et al., 2000; Anton et al., 2009). However, most of these studies had demonstrated that the addition of high-fiber, high-protein alternative ingredients to the raw material affects the texture, expansion and overall acceptability of the final products.

High-amylose corn starch is an important, industrially valuable raw material used to produce some products with special utilization. Compared to normal corn starch (NCS), which is composed of approximately $26 \%$ amylose and 74\% amylopectin, high-amylose corn starch (HACS) contains more than 50\% amylose. Moreover, the amylopectin molecular structures and functional properties of different-sized fractions of HACS and NCS were investigated to be significantly different (Lin et al., 2016).

Some previous reports showed that corn starch with a higher amylose content, ranging from 0 to $50 \%$ (db), could obtain better expansion and texture characteristics (Chinnaswamy and Hanna, 1990; Della et al, 1997). Meanwhile, high-amylose corn flour has been reported to contain more proteins, lipids, fiber and ash than normal 
corn flour, and it has a moderately high total dietary fiber content and a resistant starch content of up to $54.4 \%$ (Zhang et al., 2016; Shi and Roger, 2008). Resistant starch (RS) is a type of starch that escapes digestion in the human small intestine and can be digested in the large intestine via fermentation by colonic microflora, which cause it to resemble soluble dietary fibers and possess physiological health benefits (Englyst et al., 1992; Haralampu, 2000). The resistant starch content (RSC) of the extruded products was found to be related to the amylose content of the raw material and the extrusion conditions (Faraj et al., 2004; Kim et al., 2006).

Based on the previous research, the high-amylose corn grits were used to processes extruded products under given extrusion condition. And then, the applicability and superiority of HACG to process extruded foods were evaluated through determining the nutritional, physical and sensory parameters of HACG extrudate. It is anticipated that those results were helpful for producing of highamylose puffed food.

\section{MATERIALS AND METHODS}

\section{Raw materials and preparation}

The high-amylose corn (55.3\% amylose content) and normal corn (26.2\% amylose content) grains used as raw materials in this study were harvested in 2016 and provided by the Maize Biology and Genetic Breeding Laboratory in Northwest Arid Areas, Ministry of Agriculture, Northwest Agriculture and Forestry University. The amylose content of the raw materials mentioned above was determined with a dual wavelength iodine binding technique (Zhu et al., 2008). After removing the peel and embryo, the kernels were ground into grits using a DF-35 continuous milling machine (Wenling Linda Machinery Co, Zhejiang Province, China) and passed through a 20 mesh sieve. Both the high amylose corn grits (HACG) and normal corn grits (NCG) were air dried to a moisture content of $13.5 \%$ for use in extrusion cooking.

\section{Extrusion and extruded samples}

A SX3000-100 single screw extruder (Saixin Machinery Co., Shandong Province, China) was used to produce extrudates with a feed rate of $220 \mathrm{~g} / \mathrm{min}$, a barrel temperature of $120^{\circ} \mathrm{C}$, a screw rotational speed of $150 \mathrm{rpm}$, and a ring die exit with a $9.25 \mathrm{~mm}$ internal diameter and a $10.25 \mathrm{~mm}$ outer diameter to produce hollow extrudates. These extrusion conditions and the $13.5 \%$ moisture content for the corn grits were selected based on preliminary work to produce extruded products with a good expansion rate and texture. The extrudates were cooled for $30 \mathrm{~min}$ at room temperature and were subsequently cut into $10 \mathrm{~mm}$ long hollow cylinders with a uniform thickness using a sharp blade. Then, the extruded hollow cylinders were oven-dried at $70^{\circ} \mathrm{C}$ for $2 \mathrm{~h}$ and subsequently sealed and stored in in the dark at $4^{\circ} \mathrm{C}$ until testing. The extruded hollow cylinders were used for the physical property tests, texture profile analysis (TPA) and sensory evaluation, and the leftover extrudates were ground into fine powder for nutritional composition determination (Liu et al., 2000).

\section{Nutritional properties Chemical analyses}

For the raw materials and extruded samples, the moisture, total starch, lipid, fiber, ash and mineral content were measured by standard method (AOAC, 1995); the protein content was measured using an automatic protein analyzer (Kjeltec 8400, Foss Co, Germany) with nitrogen conversion factor of 6.25; the zein content was determined using a modified turbidimetric method (Lasson and Hoffman, 2008).

\section{Amino acid analysis}

To determine amino acid, $10 \mathrm{mg}$ of ground corn grits or extrudates powder were taken and passed through an 80 mesh sieve and hydrolyzed in $4 \mathrm{~mL}$ of $6 \mathrm{~N} \mathrm{HCl}$. The solutions were sealed in a tube under nitrogen and incubated in an oven at $110^{\circ} \mathrm{C}$ for $24 \mathrm{~h}$ (Pastorcavada et al., 2011). After derivatization with diethyl ethoxymethylenemalonate, the amino acids were determined using high-performance liquid chromatography (HPLC) with DL- $\alpha$-aminobutyric acid as an internal standard (Alaiz et al., 1992).

\section{In vitro digestion}

The in vitro digestion of samples was carried out by the enzymatic digestion method (AACC, 2009) and a Megazyme RS kit was used. Rapidly digestible starch (RDS) was the amount of complete digested starch after incubation $0.5 \mathrm{~h}$ and slowly digestible starch (SDS) was the amount of complete digested starch between incubation $0.5 \mathrm{~h}$ and $16 \mathrm{~h}$. The resistant starch (RS) was the undigested starch remaining after $16 \mathrm{~h}$ of incubation.

\section{Physical properties of the extrudate Bulk density (BD)}

The glass bead displacement method (Ali et al., 1996; Hwang and Yakawa, 2010) was used to determine the $\mathrm{BD}$ of the extruded samples. Glass beads with a diameter ranging from 0.6 to $0.8 \mathrm{~mm}$ (Shili Abrasive Industry Co., Guangzhou Province, China) were used as the displacement medium to measure the volume of the extruded hollow cylinders. The bulk densities of the extrudates were calculated as:

$\rho_{\mathrm{b}}=\left(\mathrm{W}_{\mathrm{ex}} / \mathrm{W}_{\mathrm{g}}\right) \rho_{\mathrm{gb}}$

where $\rho_{b}$ is the bulk density of the extruded sample $\left(\mathrm{g} / \mathrm{cm}^{3}\right)$; $W_{e x}$ is the extrudate mass $(\mathrm{g}) ; W_{g}$ is the mass of the glass 
beads displaced (g); and $\varrho_{g b}$ is the density of the glass beads $\left(\mathrm{g} / \mathrm{cm}^{3}\right)$, which was calculated by:

$\rho_{\mathrm{gb}}=\mathrm{W}_{\mathrm{gb}} / \mathrm{V}_{\mathrm{b}}$

where $W_{g b}$ is the mass of the glass beads in the beaker $\left(\mathrm{g} / \mathrm{cm}^{3}\right)$ and $V_{b}$ is the volume of the beaker $(\mathrm{ml})$.

Five extruded hollow cylinders were randomly selected from each sample to calculate the average density.

Radial expansion index (REI) and specific length (SL) The REI was calculated as the ratio between the crosssectional area of the extrudates and the area of the ring die nozzle (Diaz et al., 2015). The cross-sectional area of the extrudates was calculated by:

$\mathrm{S}_{\mathrm{ex}}=\left(\mathrm{W}_{\mathrm{g}} / \rho_{\mathrm{gb}}\right) / \mathrm{L}_{\mathrm{ex}}$

where $S_{e x}$ is the cross-sectional area of the extrudate $\left(\mathrm{cm}^{2}\right)$ and $L_{e x}$ is the length of the extrudate, which was measured by using a Mitutoyo500-196 electronic Vernier caliper (Shanghai Precision Instruments Co., Zhejiang Province, China) at three different points on each cylinder and recording the mean value.

The SL of the extrudates was defined as the length of the extrudate per gram.

The extruded hollow cylinders used to determine the BD were also used to determine the ER and SL.

\section{Water absorption index (WAl) and water solubility index (WSI)}

WAI and WSI were measured as suggested by Anderson et al. (1969). The ground extrudate sample (2 g, dry basis) was mixed with $25 \mathrm{~mL}$ of water in a centrifuge tube. After heating for $30 \mathrm{~min}$ in a water bath at $30{ }^{\circ} \mathrm{C}$, the heated solution was centrifuged at $3000 \times \mathrm{g}$ for $10 \mathrm{~min}$. The supernatant was placed in a Petri dish and dried at $90{ }^{\circ} \mathrm{C}$ for $4 \mathrm{~h}$ to obtain the dry solids weight and the wet sediment was weighed. The WAI and WSI of the extruded samples calculated using the following two formulas, respectively:

WAI = weight of the wet sediment / weight of the dry sample

WSI $=$ (weight of the dissolved solids in the supernatant / weight of the dry sample solids in the original sample) x 100

Three replicates were performed for each sample.

\section{Scanning electron microscopy (SEM)}

SEM was used to visualize the microstructure of the extruded samples. Both a transverse and an external examination were performed on the extruded samples. For the transverse observation, the hollow extrudates were cut with a blade at a thickness of 2-3 $\mathrm{mm}$ along the cross-section and mounted on aluminum stubs with the cross-section exposed. For the external observation, the hollow extrudates were cut into mini flakes and placed on stubs with the outer surface facing out. The specimens were sputtered with gold particles and photographed using a Hitachi S-3400N scanning electron microscope (Hitachi Ltd, Tokyo, Japan) operated at a $5.00 \mathrm{kV}$ accelerating voltage (Ahmed, 1999).

\section{Texture profile analysis (TPA)}

The TPA of the $10 \mathrm{~mm}$ extruded samples was conducted using a TVT-7600 Texture Analyzer (Perten Instruments Co., SE), as suggested by Liu et al (2000), with some modification. Each extruded hollow cylinder was placed on the loading cell, and the N673075 cylinder probe $(30 \mathrm{~mm}$ radius) was used to conduct the double-compression test cycle under the following conditions: pre-test speed, $2 \mathrm{~mm} / \mathrm{s}$; test speed, $0.4 \mathrm{~mm} / \mathrm{s}$; post-test speed, $0.4 \mathrm{~mm} / \mathrm{s}$; distance, as 50\% strain; hold time, $5 \mathrm{~s}$. The real-time, forcedeformation data were acquired using the TexCalc Profile Software (Perten Instruments Co., SE), and the texture parameters, including frangibility, hardness, adhesiveness, springiness and chewiness, were calculated and recorded as the mean of ten measurements.

\section{Sensory evaluation}

The sensory evaluation of the extruded samples was conducted by fifteen trained panelists ( 8 females and 7 males, ranging in age from 23 to 40 years) that rated the attributes in Table 1 to determine the sensory characteristics of the unflavored extrudate samples prepared from HACG and NCG.

Sensory evaluation was repeated once with a minimum 30 min break in between, and each panellist evaluated the 2 samples at each of the two sensory evaluation sessions. Each sensory attribute was evaluated on a 1 to 9 hedonic scale with 1 being dislike extremely, 5 being neither like nor dislike, and 9 being like extremely. An open area in the laboratory was selected as the test location. The panelists were provided with a questionnaire, and the specific attributes of the extrudate samples were scored (Diaz et al, 2015).

\section{Statistical analysis}

For the nutritional properties, all analyses were measured at least in duplicate. Data were subjected to the analysis of variance (ANOVA) using SPSS version 20.0 (SPSS Inc., Chicago, IL, USA). The significant differences in the means of the data were examined using Duncan's Multiple Range Test except that the mean comparison of the sensory 
Table 1: Attributes and evaluation techniques used in the descriptive analysis score sheet

\begin{tabular}{|c|c|c|}
\hline & Attributes & Evaluation techniques \\
\hline \multirow[t]{3}{*}{ Flavor attribute } & Sweetness & $\begin{array}{l}\text { Place the sample in the mouth and evaluate the sweetness perception during } \\
\text { mastication }\end{array}$ \\
\hline & Overall taste & $\begin{array}{l}\text { Place the sample in the mouth and evaluate the overall taste intensity during } \\
\text { mastication }\end{array}$ \\
\hline & Overall aftertaste & Chew the sample and evaluate the overall aftertaste intensity $10 \mathrm{~s}$ after swallowing. \\
\hline \multirow{6}{*}{$\begin{array}{l}\text { Texture } \\
\text { attribute }\end{array}$} & Hardness & Place the product between the molars and bite. Evaluate the force required to bite. \\
\hline & Frangibility & $\begin{array}{l}\text { Place the product between the front teeth and bite. Evaluate the intensity of the } \\
\text { sound }\end{array}$ \\
\hline & Coarseness & Evaluate the presence of particles that are rough to chew \\
\hline & Cohesiveness & Evaluate the degree to which particles of a sample stick together \\
\hline & $\begin{array}{l}\text { Adhesiveness (to } \\
\text { teeth) }\end{array}$ & Swallow the sample and evaluate the amount of product that remains in/on teeth \\
\hline & Chewiness & Evaluate the number of chews required to prepare the sample for swallowing \\
\hline
\end{tabular}

analysis data were conducted using the paired-samples T-test (Beddo and Kreuter, 2012).

\section{RESULTS AND DISCUSSION}

\section{Nutritional evaluation \\ Chemical composition of the raw material and extruded samples}

The chemical compositions corresponding to raw material and extruded samples are shown in Table 2. Compared to NCG extrudates, HACG extrudates showed a significantly higher $(\mathrm{P} \leq 0.05)$ content of protein, lipid, fiber, ash and a significantly lower $(\mathrm{P} \leq 0.05)$ content of starch, which can be due to the differences of these components between HACG.and NCG. An increased content of protein, fiber ash and starch in HACG and NCG extrudate was observed after extrusion, and this should be caused by the reduction in moisture content during the extrusion, as shown in Table 2. However, the lipid content in HACG and NCG extrudate displayed an slight decrease after extrusion, and this could be mainly caused by the formation of lipidamylose complex under extrusion treatment (Zhang et al., 2016).

Zein is a corn protein containing nonpolar, hydrophobic amino acids such as leucine (17-20\%), alanine (8-10\%), and proline (5-9\%). The zein content and zein-lipid interactions were suggested to influence the texture characteristics of the extruded products (Herald et al., 2002). Table 2 shows that the HACG $(4.83 \%)$ had a higher zein content than NCG $(3.43 \%)$, and the zein content of the HACG $(4.65 \%)$ and NCG extrudates $(2.81 \%)$ indicated zein was lost during the extrusion, and this can be explained by a break in the secondary structure of zein during extrusion, which was as observed by Liang (2014). Moreover, the specific mechanical energy (SME) could cause the dispersal of zein, and lipids have been widely demonstrated to act as lubricants to decrease the SME during extrusion
(Batterman-Azcona et al., 2010). The HACG with a higher lipid content produced extrudates with less zein dispersal than NCG, as shown in Table 2.

The mineral content in Table 2 shows that the HACG extrudate had nearly three times more $\mathrm{Mg}(718.63 \mathrm{mg} / \mathrm{kg})$ than the NCG extrudate $(260.47 \mathrm{mg} / \mathrm{kg}$ of $\mathrm{Mg}$ ), and the $\mathrm{Ca}, \mathrm{Fe}$ and $\mathrm{Zn}$ content in the HACG extrudate were all significantly higher $(\mathrm{P} \leq 0.05)$ than those in the NCG extrudate. The difference of mineral content between the extruded samples should be caused by the diverse mineral content between HACG and NCG. Generally, corn is considered to be poor in minerals (Brennan et al., 2013), but these results indicated that HACG is a better source of $\mathrm{Ca}, \mathrm{Mg}, \mathrm{Fe}$ and $\mathrm{Zn}$ compared to NCG.

\section{Amino acid analysis}

The amino acid profiles for the unprocessed HACG and NCG and the extruded products are shown in Table 2. The HACG had a higher total amino acid content and a higher $(\mathrm{P} \leq 0.05)$ content of most of the amino acids compared to NCG, except for histidine, which was not significantly different. The content of most of the amino acids in NCG increased due to processing, except for lysine, cysteine and arginine, which decreased significantly $(\mathrm{P} \leq 0.05)$. Lysine, cysteine and arginine are considered to be relatively unstable amino acids in high temperatures and under shear extrusion conditions, and previous studies have shown a decrease in these amino acids during extrusion, especially lysine, which was reported to be subjected to the Maillard reaction and bond formation with glucose (Ilo and Berghofer, 2003; Guzmánortiz et al., 2015). However, only arginine decreased significantly $(\mathrm{P} \leq 0.05)$ in HACG during extrusion, and a significant increase $(\mathrm{P} \leq 0.05)$ in lysine, cysteine and most of the other amino acids was observed with the exception of aspartic acid and glycine, which did not demonstrate a significant difference. This could be due to the diverse compositions of HACG, e.g., higher lipid content and lower ratio of amylopectin to amylose, 
Table 2: Physical and nutritional evaluation of the ingredients and extruded products

\begin{tabular}{|c|c|c|c|c|c|}
\hline & Parameters & HE & NE & HACG & NCG \\
\hline \multirow[t]{7}{*}{ Chemical property (g/100 g db) } & Moisture & $5.37 \pm 0.16^{b}$ & $5.48 \pm 0.18^{b}$ & $13.48 \pm 0.18^{a}$ & $13.57 \pm 0.10^{\mathrm{a}}$ \\
\hline & Protein & $7.07 \pm 0.05^{\mathrm{a}}$ & $4.53 \pm 0.03^{c}$ & $6.85 \pm 0.07^{b}$ & $4.21 \pm 0.04^{d}$ \\
\hline & Lipid & $1.48 \pm 0.03^{b}$ & $1.14 \pm 0.05^{c}$ & $1.61 \pm 0.06^{a}$ & $1.18 \pm 0.02^{c}$ \\
\hline & Fiber & $5.41 \pm 0.07^{\mathrm{a}}$ & $3.48 \pm 0.14^{b c}$ & $3.46 \pm 0.05^{b}$ & $2.74 \pm 0.04^{c}$ \\
\hline & Ash & $0.76 \pm 0.04^{\mathrm{a}}$ & $0.58 \pm 0.04^{c}$ & $0.67 \pm 0.02^{b}$ & $0.51 \pm 0.03^{d}$ \\
\hline & Starch & $76.93 \pm 0.17^{b}$ & $79.77 \pm 0.25^{a}$ & $74.43 \pm 0.57^{c}$ & $76.76 \pm 0.51^{b}$ \\
\hline & zein & $4.65 \pm 0.30^{\mathrm{a}}$ & $2.81 \pm 0.04^{c}$ & $4.83 \pm 0.21^{\mathrm{a}}$ & $3.43 \pm 0.13^{b}$ \\
\hline \multirow[t]{4}{*}{ Mineral content (mg/100 kg) } & $\mathrm{Ca}$ & $22.34 \pm 1.45^{\mathrm{a}}$ & $14.15 \pm 0.06^{b}$ & NA & NA \\
\hline & $\mathrm{Mg}$ & $718.63 \pm 2.98^{a}$ & $260.47 \pm 2.62^{b}$ & NA & NA \\
\hline & $\mathrm{Fe}$ & $19.47 \pm 0.08^{\mathrm{a}}$ & $16.90 \pm 0.09^{b}$ & NA & NA \\
\hline & $\mathrm{Zn}$ & $22.73 \pm 0.35^{\mathrm{a}}$ & $11.51 \pm 0.25^{b}$ & NA & NA \\
\hline \multirow[t]{10}{*}{ Essential amino acids ( $\mathrm{g} / 100 \mathrm{~g} \mathrm{db}$ ) } & Thr & $0.39 \pm 0.01^{\mathrm{a}}$ & $0.30 \pm 0.02^{c}$ & $0.35 \pm 0.02^{b}$ & $0.26 \pm 0.01^{c}$ \\
\hline & Cys & $0.12 \pm 0.01^{\mathrm{a}}$ & $0.05 \pm 0.00^{c}$ & $0.10 \pm 0.00^{\mathrm{b}}$ & $0.07 \pm 0.01^{c}$ \\
\hline & Val & $0.48 \pm 0.03^{a}$ & $0.34 \pm 0.01^{\mathrm{bc}}$ & $0.39 \pm 0.01^{\mathrm{b}}$ & $0.31 \pm 0.02^{c}$ \\
\hline & Met & $0.24 \pm 0.01^{\mathrm{a}}$ & $0.17 \pm 0.02^{b}$ & $0.17 \pm 0.01^{b}$ & $0.12 \pm 0.00^{c}$ \\
\hline & lle & $0.34 \pm 0.00^{\mathrm{a}}$ & $0.26 \pm 0.01^{\mathrm{b}}$ & $0.25 \pm 0.00^{\mathrm{b}}$ & $0.19 \pm 0.00^{c}$ \\
\hline & Leu & $1.47 \pm 0.04^{\mathrm{a}}$ & $1.22 \pm 0.04^{\mathrm{b}}$ & $0.86 \pm 0.01^{c}$ & $0.75 \pm 0.02^{d}$ \\
\hline & Try & $0.53 \pm 0.01^{\mathrm{a}}$ & $0.27 \pm 0.02^{b}$ & $0.24 \pm 0.01^{b}$ & $0.17 \pm 0.01^{c}$ \\
\hline & Phe & $0.38 \pm 0.00^{\mathrm{a}}$ & $0.40 \pm 0.03^{a}$ & $0.32 \pm 0.01^{b}$ & $0.25 \pm 0.01^{c}$ \\
\hline & Lys & $0.63 \pm 0.01^{\mathrm{a}}$ & $0.08 \pm 0.01^{d}$ & $0.27 \pm 0.01^{b}$ & $0.18 \pm 0.01^{c}$ \\
\hline & His & $0.90 \pm 0.02^{\mathrm{a}}$ & $0.32 \pm 0.02^{b}$ & $0.32 \pm 0.01^{b}$ & $0.27 \pm 0.01^{b}$ \\
\hline \multirow[t]{7}{*}{ Non-essential amino acids ( $\mathrm{g} / 100 \mathrm{~g} \mathrm{db}$ ) } & Arg & $0.31 \pm 0.00^{\mathrm{b}}$ & $0.21 \pm 0.01^{d}$ & $0.37 \pm 0.00^{\mathrm{a}}$ & $0.25 \pm 0.01^{c}$ \\
\hline & Asp & $0.60 \pm 0.02^{\mathrm{a}}$ & $0.45 \pm 0.02^{b}$ & $0.57 \pm 0.02^{\mathrm{a}}$ & $0.42 \pm 0.02^{b}$ \\
\hline & Ala & $0.72 \pm 0.01^{\mathrm{a}}$ & $0.61 \pm 0.01^{\mathrm{b}}$ & $0.55 \pm 0.01^{c}$ & $0.43 \pm 0.02^{d}$ \\
\hline & Glu & $1.74 \pm 0.06^{\mathrm{a}}$ & $1.46 \pm 0.03^{b}$ & $1.22 \pm 0.04^{c}$ & $0.98 \pm 0.01^{d}$ \\
\hline & Gly & $0.37 \pm 0.01^{\mathrm{a}}$ & $0.23 \pm 0.00^{b}$ & $0.36 \pm 0.02^{\mathrm{a}}$ & $0.25 \pm 0.02^{b}$ \\
\hline & Pro & $2.06 \pm 0.02^{\mathrm{a}}$ & $1.77 \pm 0.02^{b}$ & $1.49 \pm 0.01^{c}$ & $1.22 \pm 0.03^{d}$ \\
\hline & Ser & $0.45 \pm 0.01^{\mathrm{a}}$ & $0.36 \pm 0.01^{\mathrm{b}}$ & $0.37 \pm 0.02^{b}$ & $0.27 \pm 0.00^{c}$ \\
\hline
\end{tabular}

$\mathrm{HE}$, high-amylose corn grits extrudate; NE, normal corn grits extrudate; HACG, high-amylose corn grits; NCG, normal corn grits. Ca, calcium; Mg, magnesium; Fe, iron; Zn, zinc; Cys, cysteine; Phe, phenylalanine; His, histidine; lle, isoleucine; Leu, leucine; Lys, lysine; Met, methionine; Tyr, tyrosine; Thr, threonine; Val, valine; Ala, alanine; Arg, arginine; Asp, aspartic acid; Gly, glycine; Glu, glutamic acid; Pro, proline; Ser, serine. NA, Non-analyzed. Mean values \pm standard

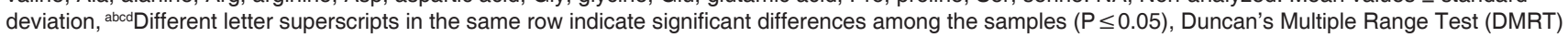

which result in a lower melt viscosity, less mechanical energy and limited amino acid loss, as suggested by Ilo and Berghofer (2003). Finally, the total amino acid content and the content of most of the amino acids in the HACG extrudate were significantly higher $(\mathrm{P} \leq 0.05)$ than those in the NCG extrudate. Phenylalanine was the only exception and did not demonstrate a significant difference. This result indicated the higher nutritive value of amino acids in the HACG extrudate.

\section{In vitro digestion}

Figure 1 shows the enzymatic in vitro digestion of four samples. The RS, SDS, and RDS contents in each sample were normalized to total starch content. Obviously, The RDS and SDS made up the main part of the starch of each sample, and more RDS and less SDS formed after extrusion treatment in $\mathrm{HE}$ and NE, making the samples more vulnerable to digestion. The NCG extrudate was supposed to be easier to digest because of its higher $(\mathrm{P} \leq 0.05) \mathrm{RDS}$ content $(94.31 \%)$ than the HACG extrudate (92.16\%). Nevertheless, the RS in samples, possessing physiological health benefits, should be concerned more.

The RS content of HACG $(23.11 \%)$ was over 4 times that of NCG $(5.38 \%)$. The extrusion process damaged the native RS, caused gelatinization and retrogradation, and reformed the RS (Nedersuárez et al., 2016). However, the extrudates of HACG and NCG had RS contents of $2.89 \%$ and $1.01 \%$, respectively, which indicated a minor amount of RS was rebuilt during the extrusion. In general, the RS content increased as the moisture content and extrusion temperature increased (Chinfu et al., 2010). The low RS content in the HACG extrudate can be attributed to the lower extrusion temperature $\left(120^{\circ} \mathrm{C}\right)$ and moisture content (13.5\%). Even so, the RS content of the HACG extrudate was almost 3 times of that of the NCG extrudate, which indicated the HACG extrudate could be treated as a healthcare food playing the key role of RS in 
vivo digestion, such as enhancing intestinal peristalsis and promoting sugar balance (Englyst et al., 1992; Haralampu, 2000). The increased RS content could be due to the higher amylose content in HACG. The higher amylose content results in more chances to avoid starch retrogradation or excessive dextrinization which limit the formation of RS (Nedersuárez et al., 2016).

\section{Physical properties of the extruded products The appearance and microstructure of the HACG extrudates}

Figure $2 \mathrm{a}$ shows the appearance of the extruded products and the cut hollow cylinders. Compared to the NCG extrudates, which had concentrated wrinkles on their surface, the HACG extrudates had a much smoother surface. Meanwhile, the hollow cylinders cut from the HACG extrudates had slightly smaller external diameters than those cut from the NCG extrudates, which means HACG extrudates demonstrated a lower expansion index.

As seen in Fig. 2b, more and smaller air cells can be observed in the cross-section of the HACG extrudates compared to the NCG extrudates (Fig. 2c), which gave the HACG extrudates a more sponge-like structure. The air cells in the extrudate formed after the formation of the melt matrix bubbles, which formed as the water

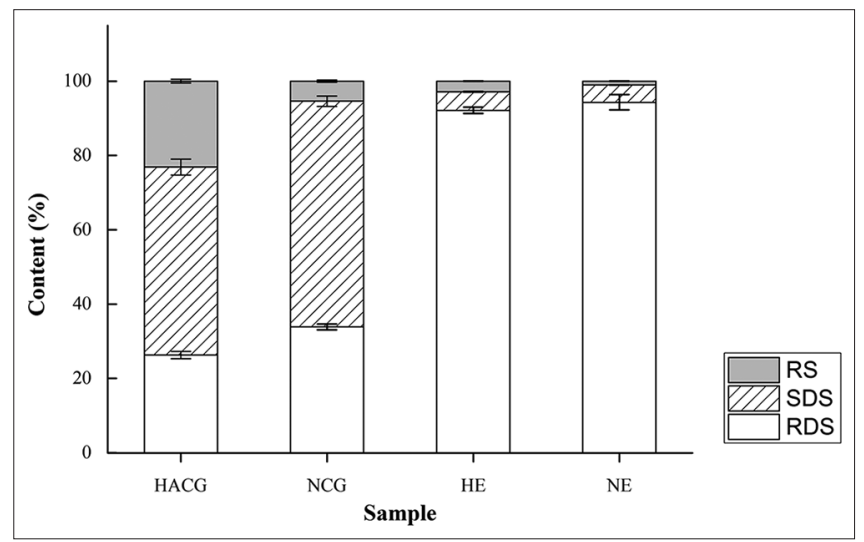

Fig 1. Starch fractions of digestion in vitro of the ingredients and extruded products: $\mathrm{HE}$, high-amylose corn grits extrudate; NE, normal corn grits extrudate; HACG, high-amylose corn grits; NCG, normal corn grits. RDS, rapidly digestible starch; SDS, slowly digestible starch; RS, resistant starch. vapor expanded outward during the flow through the die. However, the increased protein, lipid, fiber and amylose content in the HACG and the formation of the amyloselipid complex during the extrusion cooking can inhibit the melt matrix swell by affecting the water distribution in the matrix and inhibit the extensional properties of the melt matrix (Larrea et al., 2005; Shirani and Ganesharanee, 2009). As a result, smaller and denser cells were formed in the HACG extrudates. Moreover, because of the contribution from the formation of more complexes, such as the amylose-lipid complex in the melt matrix, the cell walls of the HACG extrudates should be tougher and were expected to change the texture properties of the extrudates (Thachil et al., 2014). Fig. 2d and e show the external images of the HACG extrudate and NCG extrudate, respectively. The surface of the NCG extrudate was filled with fissures and bubbles of different sizes, which led to a rugged surface. The fissures could be caused by a rupture of the melt matrix, if the water vapor swelled outwards. However, smaller and more uniform bubbles were embedded in the flatter surface of the HACG extrudate, rather than bubbles of different sizes separated by fissures like the NCG extrudate. This surface characteristic of the HACG extrudate could be due to the lower expansion capacity of the HACG melt matrix as previously suggested.

\section{Physical parameters of the extruded samples}

The physical parameters of the extruded samples are shown in Table 3. The HACG extrudate had a slightly lower radial expansion value compared to the NCG extrudate. This can be explained by the smaller size of the air cells in the HACG extrudate. The higher protein, lipid, fiber, and amylose content in the HACG contributed to the lower radial expansion in the extrudate. Regarding the extrudate expansion, most of the related studies used the radial expansion ratio as the measure of the expansion quality. However, some earlier research showed that extrudate expansion occurs in both the radial and axial directions during extrusion cooking. The radial expansion is thought to be dependent on the elasticity of the melt matrix, which is mainly determined by the amylopectin network (Liu et al, 2010). The higher amylose/

Table 3: Physical parameters and texture properties of the extrudate samples

\begin{tabular}{lccccc}
\hline Sample & BD $(\mathbf{m g} / \mathbf{m l})$ & ERI & SL $(\mathbf{c m} / \mathbf{g})$ & WSI $(\%)$ & WAI \\
HE & $57.94 \pm 1.34^{\mathrm{b}}$ & $45.47 \pm 1.08^{\mathrm{b}}$ & $7.34 \pm 0.34^{\mathrm{a}}$ & $43.25 \pm 1.00^{\mathrm{b}}$ & $3.69 \pm 0.01^{\mathrm{b}}$ \\
$\mathrm{NE}$ & $66.65 \pm 2.54^{\mathrm{a}}$ & $59.16 \pm 1.27^{\mathrm{a}}$ & $4.96 \pm 0.29^{\mathrm{b}}$ & $72.82 \pm 2.72^{\mathrm{a}}$ & $2.45 \pm 0.02^{\mathrm{a}}$ \\
& Frangibility & Hardness & Springiness & Cohesiveness & Chewiness \\
& $68.79 \pm 2.14^{\mathrm{a}}$ & $70.21 \pm 2.73^{\mathrm{a}}$ & $0.90 \pm 0.30^{\mathrm{a}}$ & $0.32 \pm 0.02^{\mathrm{a}}$ & $18.53 \pm 3.22^{\mathrm{a}}$ \\
& $64.21 \pm 2.95^{\mathrm{b}}$ & $71.57 \pm 3.32^{\mathrm{a}}$ & $0.86 \pm 0.25^{\mathrm{a}}$ & $0.26 \pm 0.02^{\mathrm{b}}$ & $15.89 \pm 3.36^{\mathrm{a}}$
\end{tabular}

HE, high-amylose corn grits extrudate; NE, normal corn grits extrudate. BD, bulk density; ERI, radial expansion index; SL, specific length; WSI, water

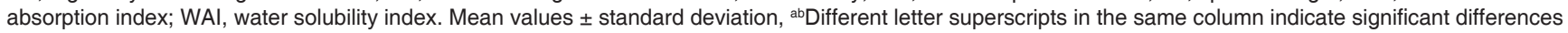
among the samples $(\mathrm{P} \leq 0.05)$, Duncan's Multiple Range Test (DMRT) 

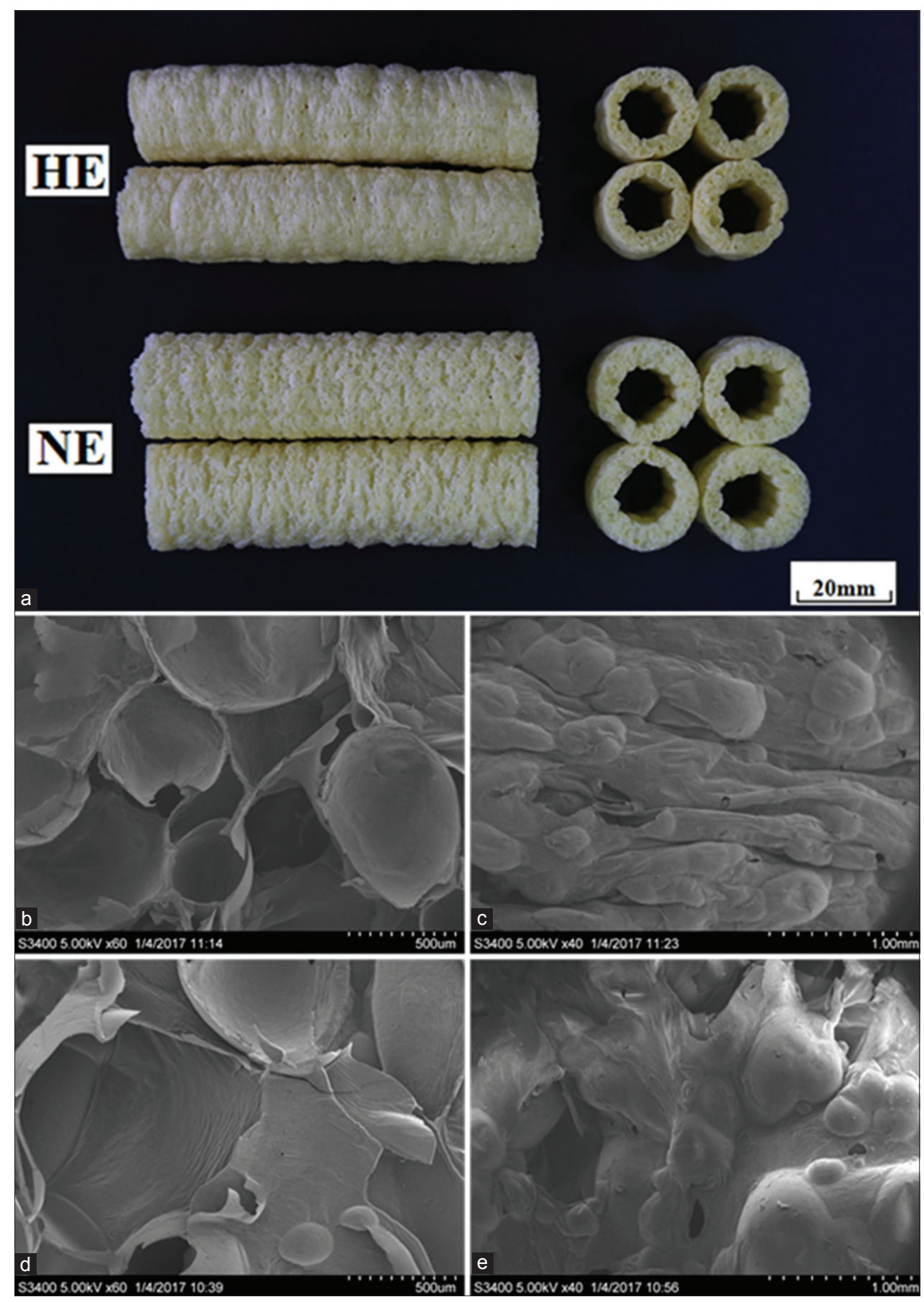

Fig 2. Extruded products and SEM images of the transverse and external sides of the extrudates: (a) appearance of the HE (HACG extrudates) and NE (NCG extrudates); (b) transverse image of HE; (c) external image of HE; (d) transverse image of NE; (e) external image of NE.

amylopectin ratio might be the cause of the lower radial expansion in the HACG extrudate. The axial expansion is favored by a lower melt viscosity, which could lead to an increase in the ratio of the extrudate velocity after expansion to the velocity of the extrudate inside the die (Alvarez-Martinez et al., 1988). High-amylose corn flour was studied and had a much lower pasting viscosity value than normal corn flour because of the different amylose and lipid content and amylopectin branch chain length distribution (Zhang et al., 2016). Based on the above explanation, the extrudates produced using HACG were expected to have a higher axial expansion at the expense of a lower radial expansion value. The expected "higher axial expansion" in the HACG extrudate was supported by the SL, which is a key indicator of the axial expansion. As shown in Table 3, the HACG extrudate had a higher SL value $(7.34 \mathrm{~cm} / \mathrm{g})$ compared to the NCG extrudate $(4.96 \mathrm{~cm} / \mathrm{g})$. 
Some research has shown that an inverse relationship of $\mathrm{BD}$ and REI existed in the extrudate produced under various extrusion conditions (Shirani and Ganesharanee, 2009; Gat and Ananthanarayan, 2015). However, in this study, the extrudate with a lower BD and REI were produced using HACG. Similarly, the bulk density of corn flour extrudate was decreased with increasing of high-amylose starch content in flour in previous research (Koester, 2008). In this study, the lower BD and REI of the HACG extrudate could be the result of the higher axial expansion.

The WAI and WSI values of the extruded samples showed an inverse relation, which agreed with the results from other related studies (Guzmánortiz et al., 2015; Shirani and Ganesharanee, 2009). A higher WAI indicates the presence of larger starch fragments, and a higher WSI means more starch has been dextrinized. Table 3 shows that the HACG extrudate had a lower WSI and a higher WAI, which indicated the HACG extrudate possessed a lower degree of gelatinization. The lower WSI was mainly caused by the higher amylose content because of the inverse relationship between the amylose content and solubility (González et al., 2013). The lower amylopectin/amylose ratio and higher crude fiber content contributed to the higher WAI. In general, high-amylose corn starch is more difficult to dextrinize than normal corn starch, and crude fiber is considered to have a higher water absorption capacity (Vanier et al., 2016). A similar positive relationship between the WAI value and fiber content has been widely reported (Shirani and Ganesharanee, 2009; Thachil et al., 2014).

\section{Texture profile analysis (TPA)}

Figure $3 \mathrm{a}$ and $\mathrm{b}$ show the typical force-time curves obtained from the TPA during the compression of the extruded samples. Less jaggedness was observed in the force-time curve of the HACG extrudate during the first compression, which indicated fewer fractures in the internal structure. The texture parameters corresponding to the HACG extrudates and NCG extrudates are shown in Table 3. The frangibility and cohesiveness of the HACG extrudates were significantly higher $(P \leq 0.05)$ than that of the NCG extrudates. In this study, the instrumental frangibility was expressed using the force value corresponding to the first apparent peak (point A in Fig. 3a and b) in the force-time texture profile curve (Halek et al., 2007; Szczesniak and Hall, 2007). The size of the cell as well as the thickness and toughness of a cell wall can affect the rupture of the cells and, indirectly, the frangibility (Bouvier et al., 1997). The fact that the HACG extrudates that were composed of smaller air cells had a higher frangibility was contrary to some previous studies in which the extrudates with a smaller cell size had a lower frangibility (Diaz et al., 2015). This could be because, compared to the cell size, the

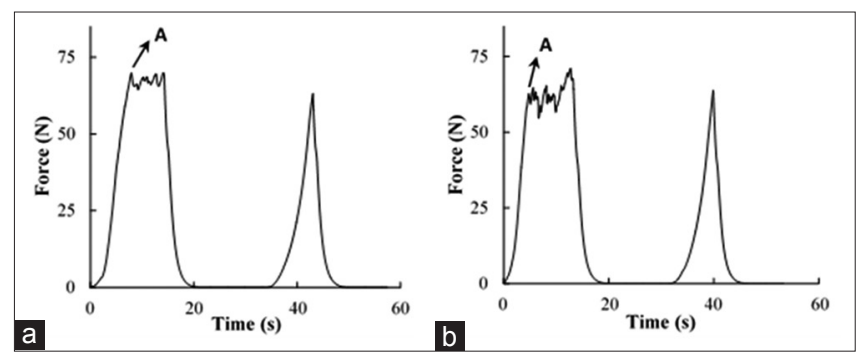

Fig 3. Typical force-time curves of the extruded samples obtained from TPA: (a) HACG extruded sample; (b) NCG extruded sample. A, the first apparent peak of the curve.

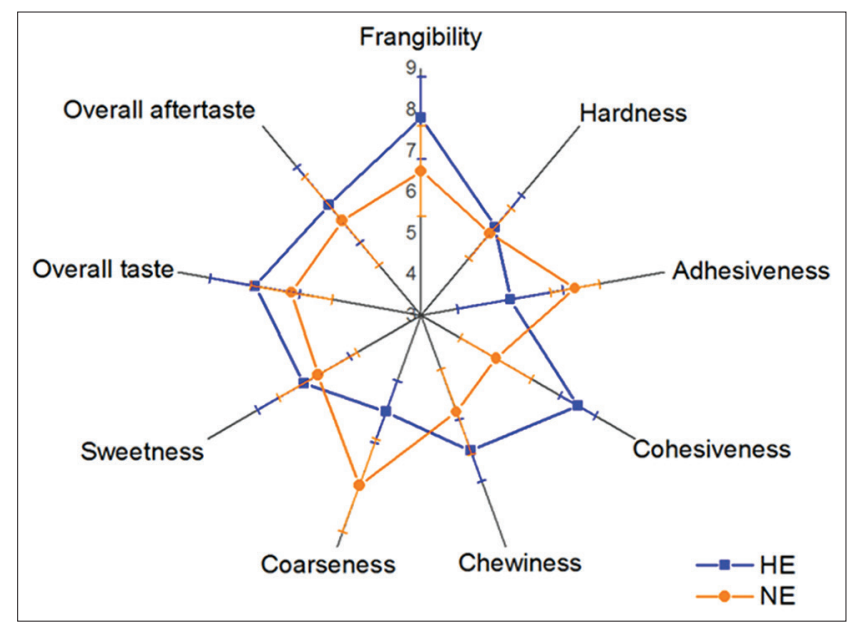

Fig 4. Sensory parameters of the extrudate samples.

toughness of the cell wall and the higher content of the amylose-lipid complexes, protein-lipid complexes and fibers in the HACG extrudate have more influence against cell rupture and caused the first breaking peak in the force/time texture profile curve to have a higher value. Cohesiveness was defined as the ratio of the second peak area to the first peak area and indicated the strength of the internal binding force to keep the extrudate from breaking into slags during compression and chewing. Smaller and compact air cells with tough walls lead to a higher cohesiveness in the HACG extrudates.

Meanwhile, the mean values of the texture parameters indicated that the HACG extrudates had a slightly lower hardness and slightly higher springiness and chewiness compared to the NCG extrudates, but the variance corresponding to these parameters was not significant at the 0.05 level. This could be because the different BD values weakened the influence of the size, wall thickness and toughness of the air cells in the extruded samples.

\section{Sensory analysis}

The sensory evaluations of the extrudate samples are shown in Fig. 4. Compared to the NCG extrudate, the HACG extrudate had significantly higher $(\mathrm{P} \leq 0.05)$ values for frangibility, cohesiveness, chewiness and overall taste 
and significantly lower $(\mathrm{P} \leq 0.05)$ values for coarseness and adhesiveness (to teeth). The differences in the sweetness, hardness and overall aftertaste were not significant $(\mathrm{P}>0.05)$. These evaluations indicated that the HACG extrudates were crunchier, not as easy to slag, had fewer hard particles and obtained a better overall taste compared to the NCG extrudates.

The frangibility, hardness and cohesiveness determined via TPA were consistent with the values measured via sensory analysis, but chewiness was an exception. The difference in the instrumental chewiness between the extrudates of HACG and NCG was not significant ( $\mathrm{P}>0.05)$, although the HACG extrudates obtained a slightly higher mean value. However, the sensory chewiness of the HACG extrudate was rated at a significantly higher $(\mathrm{P} \leq 0.05)$ value than that of the NCG extrudate. Halek et al. (2007) determined that the moisture content of the extrudate significantly affects the texture properties. In this study, the difference in the chewiness evaluation could be due to the difference in chewiness caused by the addition of saliva upon tongue stirring during the sensory evaluation.

\section{CONCLUSION}

Compared to the NCG extrudate, the HACG extrudate had better nutritional properties, such as higher protein, lipid, fiber, minerals and most of the amino acids content; better texture properties including higher frangibility and cohesiveness, which were validated by a sensory evaluation which also showed better chewiness, overall taste and lower coarseness and adhesiveness (to teeth) in the HACG extrudate. It can be concluded that high-amylose corn grits can serve as an excellent raw material for processing extruded foods.

\section{ACKNOWLEDGMENTS}

This research was conducted in the College of Agronomy, Northwest A\&F University, and supported by research grants from Shaanxi Province Comprehensive Project (grant number 2015KTZDNY01-01-01), Yangling District technical Plan Project (grant number 2014NV-01) and Zhongying Tang Breeding Special Funding (grant number A212021205).

\section{Author contributions}

Dongwei guo and Jiquan Xue designed the study. Linsan Liu and Silu Li interpreted the results and drafted the manuscript. Yuyue Zhong, Yibo Li and Jianzhou Qu collected the raw material and processed the extrusion. Jiaojiao Feng, Shutu Xu and Renhe Zhang collected the test data.

\section{REFERENCES}

AACC. 2009. Approved Methods of the American Association of Cereal Chemists (Method 32-40). American Association of Cereal Chemists, Inc., St. Paul., MN.

AOAC. 1995. Official Methods of Analysis. $16^{\text {th }}$ ed. AOAC International, Washington.

Ahmed, Z. S. 1999. Physico-chemical, structural and sensory quality of corn-based flax-snack. Mol. Nutr. Food Res. 43(4): 253-258.

Alaiz, M., J. L. Navarro, J. Girón and E. Vioque. 1992. Amino acid analysis by high-performance liquid chromatography after derivatization with diethyl ethoxymethylenemalonate. J. Chromatogr. A. 591(1-2): 181-186.

Ali, Y., M. A. Hanna and R. Chinnaswamy. 1996. Expansion characteristics of extruded corn grits. LWT Food Sci. Technol. 29(8): 702-707.

Alvarez-Martinez, L., K. P. Kondury and J. M. Harper. 1988. A general model for expansion of extruded products. J. Food Sci. 53(2): 609-615.

Anderson, R. A., H. F. Conway, V. F. Pfeifer and E. J. Griffin. 1969. Gelatinization of corn grits by roll-and extrusion-cooking. Cereal Sci. Today. 14: 4-12.

Anton, A. A., R. G. Fulcher and S. D. Arntfield. 2009. Physical and nutritional impact of fortification of corn starch-based extruded snacks with common bean (Phaseolus vulgaris L.) flour: Effects of bean addition and extrusion cooking. Food Chem. 113(4): 989-996.

Batterman-Azcona, S. J., J. W. Lawton and B. R. Hamaker. 2010. Microstructural changes in zein proteins during extrusion. Scanning. 21(21): 212-216.

Beddo, V. C. and F. Kreuter. 2012. A handbook of statistical analyses using spss. J. Stat. Softw. 11(b03): 633.

Bouvier, J. M., R. Bonneville and A. Goullieux. 1997. Instrumental methods for the measurement of extrudate crispness. Agro Food Industry Hi Tech. 8(1): 16-19.

Brennan, M. A., E. Derbyshire, B. K. Tiwari and C. S. Brennan. 2013. Ready-to-eat snack products: The role of extrusion technology in developing consumer acceptable and nutritious snacks. Int. J. Food Sci. Tech. 48(5): 893-902.

Chinfu, C., M. C. Wu, B. Nurtama and J. S. Lin. 2010. Manufacture of resistant starch by different physical modifications and storage times. J. Food Agric. Environ. 8(3): 230-234.

Chinnaswamy, R. and M. A. Hanna. 1990. Macromolecular and functional properties of native and extrusion-cooked corn starch. Cereal Chem. 67(5): 490-499.

Della, V. G., B. Vergnes, P. Colonna and A. Patria. 1997. Relations between rheological properties of molten starches and their expansion behavior in extrusion. J. Food Eng. 31(3): 277-295.

Diaz, J. M. R., J. P. Suuronen, K. C. Deegan, R. Serimaa, H. Tuorila and K. Jouppila. 2015. Physical and sensory characteristics of corn-based extruded snacks containing amaranth, quinoa and kañiwa flour. Lebensm. Wiss. Technol. 64(2): 1047-1056.

Englyst, H. N., S. M. Kingman and J. H. Cummings. 1992. Classification and measurement of nutritionally important starch fractions. Eur. J. Clin. Nutr. 46 Suppl 2: S33-S50.

Faraj, A., T. Vasanthan and R. Hoover. 2004. The effect of extrusion cooking on resistant starch formation in waxy and regular barley flours. Food Res. Int. 37(5): 517-525.

Ficarella, A., M. Milanese and D. Laforgia. 2006. Numerical study of the extrusion process in cereals production: Part I. Fluid-dynamic analysis of the extrusion system. J. Food Eng. 73(2): 103-111. 
Gat, Y. and L. Ananthanarayan. 2015. Effect of extrusion process parameters and pregelatinized rice flour on physicochemical properties of ready-to-eat expanded snacks. J. Food Sci. Technol. 52(5): 1-12.

González, R. J., E. P. Cavada, J. V. Pea, R. L. Torres, D. M. D. Greef and S. R. Drago. 2013. Extrusion conditions and amylose content affect physicochemical properties of extrudates obtained from brown rice grains. Int. J. Food Sci. Tech. 2013, 8.

Gujral, H. S., N. Singh and B. Singh. 2001. Extrusion behaviour of grits from flint and sweet corn. Food Chem. 74(3): 303-308.

Guzmánortiz, F. A., H. Hernándezsánchez, H. Yeemadeira, M. E. San, M. C. Roblesramírez, M. Rojaslópez, J. J. Berríos and R. Moraescobedo. 2015. Physico-chemical, nutritional and infrared spectroscopy evaluation of an optimized soybean/corn flour extrudate. J. Food Sci. Technol. 52: 4066-4077.

Halek, G. W., S. W. Paik and K. L. B. Chang. 2007. The effect of moisture content on mechanical properties and texture profile parameters of corn meal extrudates. J. Texture Stud. 20: 43-56.

Haralampu, S. G. 2000. Resistant starch--a review of the physical properties and biological impact of RS3. Carbohydr. Polym. 41(3): 285-292.

Herald, T. J., E. Obuz, W. W. Twombly and K. D. Rausch. 2002. Tensile properties of extruded corn protein low-density polyethylene films. Cereal Chem. 79(2): 261-264.

Hwang, M. P. and K. I. H. Yakawa. 2010. Bulk densities of cookies undergoing commercial baking processes. J. Food Sci. 45(5): 1400-1402.

Ilo, S. and E. Berghofer. 2003. Kinetics of lysine and other amino acids loss during extrusion cooking of maize grits. J. Food Sci. 68(2): 496-502.

Kasemsadeh, M. 2011. Introduction to extrusion technology. In: Maskan, M. and A. Altan, editors. Advances in Food Extrusion Technology, CRC Press, Boca Raton, pp. 1-22.

Kim, J. H., E. J. Tanhehco and P. K. W. Ng. 2006. Effect of extrusion conditions on resistant starch formation from pastry wheat flour. Food Chem. 99(4): 718-723.

Koester, E. 2008. Properties of Extruded White Corn Flour-high Amylose Corn Starch Puffs. M. S. Dissertation, University of Missouri, Missouri.

Larrea, M. A., Y. K. Chang and F. Martinezbustos. 2005. Some functional properties of extruded orange pulp and its effect on the quality of cookies. LWT Food Sci. Technol. 38(3): 213-220.

Larson, J. A. and P. C. Hoffman. 2008. Method to quantify prolamin proteins in corn that are negatively related to starch digestibility in ruminants. J. Dairy Sci. 91(5): 4834-4839.

Liang, X. 2014. Effects of extrusion and starch removal pretreatment on zein proteins extracted from corn gluten meal. Cereal Chem. 91(5): 496-501.
Lin, L., C. Cai, R. G. Gilbert, E. Li, J. Wang and C. Wei. 2016 Relationships between amylopectin molecular structures and functional properties of different-sized fractions of normal and high-amylose maize starches. Food Hydrocolloid. 52: 359-368.

Liu, W., P. J. Halley and R. G. Gilbert. 2010. Mechanism of degradation of starch, a highly branched polymer, during extrusion. Macromolecules. 43(6): 2855-2864.

Liu, Y., F. Hsieh, H. Heymann and H. E. Huff. 2000. Effect of process conditions on the physical and sensory properties of extruded oat-corn puff. J. Food Sci. 65(7): 1253-1259.

Nedersuárez, D., C. A. Amayaguerra, A. Quinteroramos, E. Pérezcarrillo, M. G. Alanísguzmán, J. G. Báezgonzález, C. L. Garcíadíaz, M. A. Núñezgonzález, D. Lardizábalgutiérrez and J. A. Jiménezcastro. 2016. Physicochemical changes and resistant-starch content of extruded cornstarch with and without storage at refrigerator temperatures. Molecules. 21(8): 1064.

Pastorcavada, E., S. R. Drago, R. J. González, R. Juan, J. E. Pastor, M. Alaiz and J. Vioque. 2011. Effects of the addition of wild legumes (Lathyrus annuus and Lathyrus clymenum) on the physical and nutritional properties of extruded products based on whole corn and brown rice. Food Chem. 128(4): 961-967.

Shi, Y. C. and J. Roger. 2008. Structural features of resistant starch. In: McCleary, B.V. and L. Prosky, editors. Advanced Dietary Fibre Technology. Blackwell Science, lowa, pp. 430-439.

Shirani, G. and R. Ganesharanee. 2009. Extruded products with fenugreek (Trigonella foenum-graecium) chickpea and rice: Physical properties, sensory acceptability and glycaemic index. J. Food Eng. 90(1): 44-52.

Szczesniak, A. S. and B. J. Hall. 2007. Application of the general foods texturometer to specific food products. J. Texture Stud. 6(1): 117-138.

Thachil, M. T., M. K. Chouksey and V. Gudipati. 2014. Amylose-lipid complex formation during extrusion cooking: Effect of added lipid type and amylose level on corn-based puffed snacks. Int. J. Food Sci. Tech. 49(2): 309-316.

Vanier, N. L., V. Vamadevan, G. P. Bruni, C. D. Ferreira, V. Z. Pinto, K. Seetharaman, E. D. R. Zavareze, M. C. Elias and J. D. J. Berrios. 2016. Extrusion of rice, bean and corn starches: Extrudate structure and molecular changes in amylose and amylopectin. J. Food Sci. 81(12): 2932-2938.

Zhang, X., Y. Chen, R. Zhang, Y. Zhong, Y. Luo, S. Xu, J. Liu, J. Xue and D. Guo. 2016. Effects of extrusion treatment on physicochemical properties and in vitro digestion of pregelatinized high amylose maize flour. J. Cereal Sci. 68: 108-115.

Zhu, T., D. S. Jackson, R. L. Wehling and B. Geera. 2008. Comparison of amylose determination methods and the development of a dual wavelength iodine binding technique. Cereal Chem. 85(1): 51-58. 